\title{
DESENHO E ORIENTAÇÃO DO TRANSEUNTE DA UEFS
}

$\underline{\text { Vitor Mateus Pimentel de Jesus }^{1} \text {; Robson Luiz Santana Barbosa }}{ }^{2}$

1. Bolsista PIBIC/CNPq, Graduando em Engenharia Civil , Universidade Estadual de Feira de Santana, e-mail: primuvitu@gmail.com

2. Orientador, Departamento de Letras e Artes, Universidade Estadual de Feira de Santana, e-mail: ssanttana@hotmail.com,

PALAVRAS-CHAVE: Desenho; Cartografia; Sinalização.

\section{INTRODUÇÃO}

A cartografia é a ciência da representação gráfica que gera como produto final um mapa. Em suma, é a gênese que trata da concepção, difusão, utilização e estudo dos mapas (NUNES, 2016).

Os mapas têm como finalidade ser um resumo do mundo real, utilizando símbolos, cores e traços que devem ser facilmente interpretados por um usuário em potencial. Cada tipo de mapa exige sua característica técnica específica que está relacionada com seu usuário, atendendo às atividades mais complexas, como cartas de navegação marítima e aérea, e também as mais simples, rotas de transporte rodoviário e turístico (CASTRO, 2004).

Assim, um mapa, como forma de comunicação por sinais, deve satisfazer algumas exigências: ser relevante para o leitor; ser facilmente entendido; ser facilmente identificado; ser facilmente lido e manipulado (NZ TRANSPORT AGENCY, 2008).

\section{MATERIAL E MÉTODOS}

Para a execução deste projeto, primeiramente foi realizado um levantamento de informações existentes a cerca do mapeamento da universidade. De posse das informações topográficas, através do software livre GIMP 2.10.18, foi desenvolvido o mapa, tendo como base a representação fiel do terreno da universidade Para maior precisão e identificação da área, vegetação e construções, foram utilizadas também fotos 
via satélite pela ferramenta do Google Maps. A estética do mapa tem como referência a Especificação Internacional para Mapas de Orientação) (IOF (CBO, 2020).

\section{RESULTADOS E/OU DISCUSSÃO}

O tipo de mapa desenvolvido foi um mapa guia que tem características de vegetação, trechos de rodovia, ruas e estradas, rede de caminhos, praças e prédios em detalhes. Esse guia possui todas as características que são visíveis no terreno de forma clara e legível, fornecendo importantes pontos de referência.

Supondo que um visitante está no pórtico e precisa chegar até a biblioteca. Ele recebe como instrução que esta mesma fica à esquerda da Reitoria, prédio que a entrada da universidade, o visitante terá uma visão geral e detalhada do local, como mostra a figura abaixo: pessoa também não sabe como encontrar. Tendo um mapa em uma placa fixa próxima a

FIGURA 1- Plano geral do mapa desenvolvido para orientação (Fonte: o próprio autor).

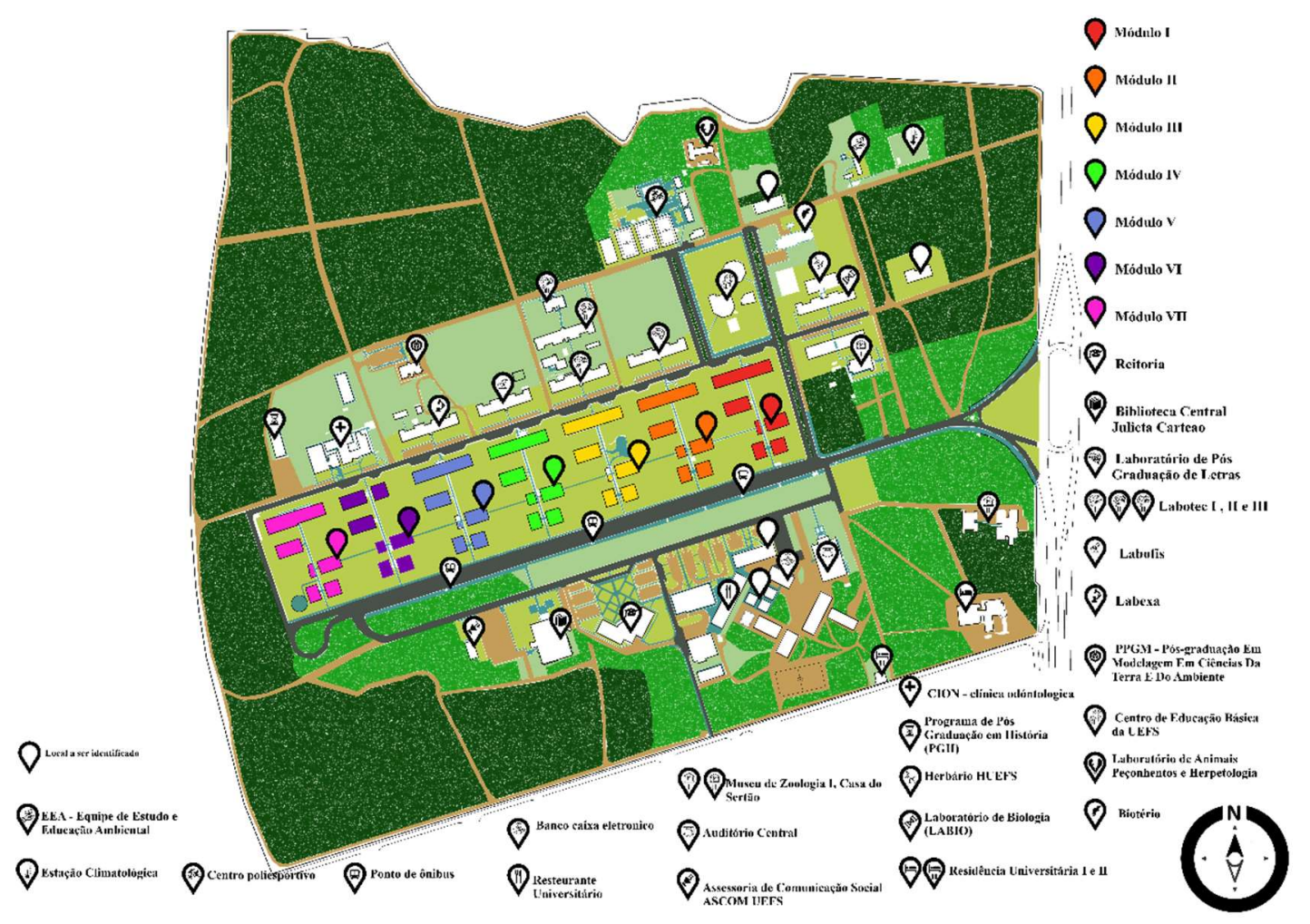


FIGURA 2- Visão detalhada do mapa baseado na simulação citada

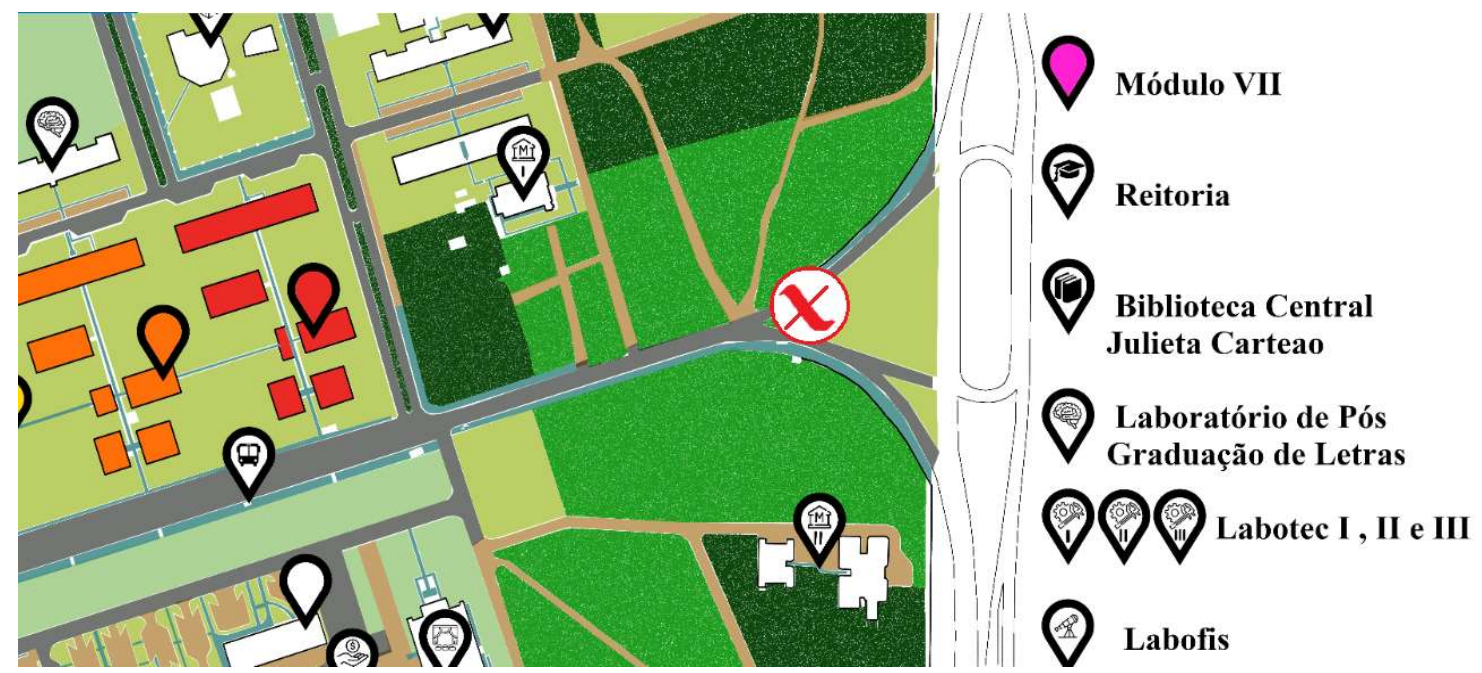

(Fonte: o próprio autor).

Na simulação podemos identificar onde o visitante está situado no mapa, através da marcação do X. Em seguida, este deverá procurar o símbolo referente à Reitoria, como mostra a Figura 3.

FIGURA 3- Visão da reitoria no mapa

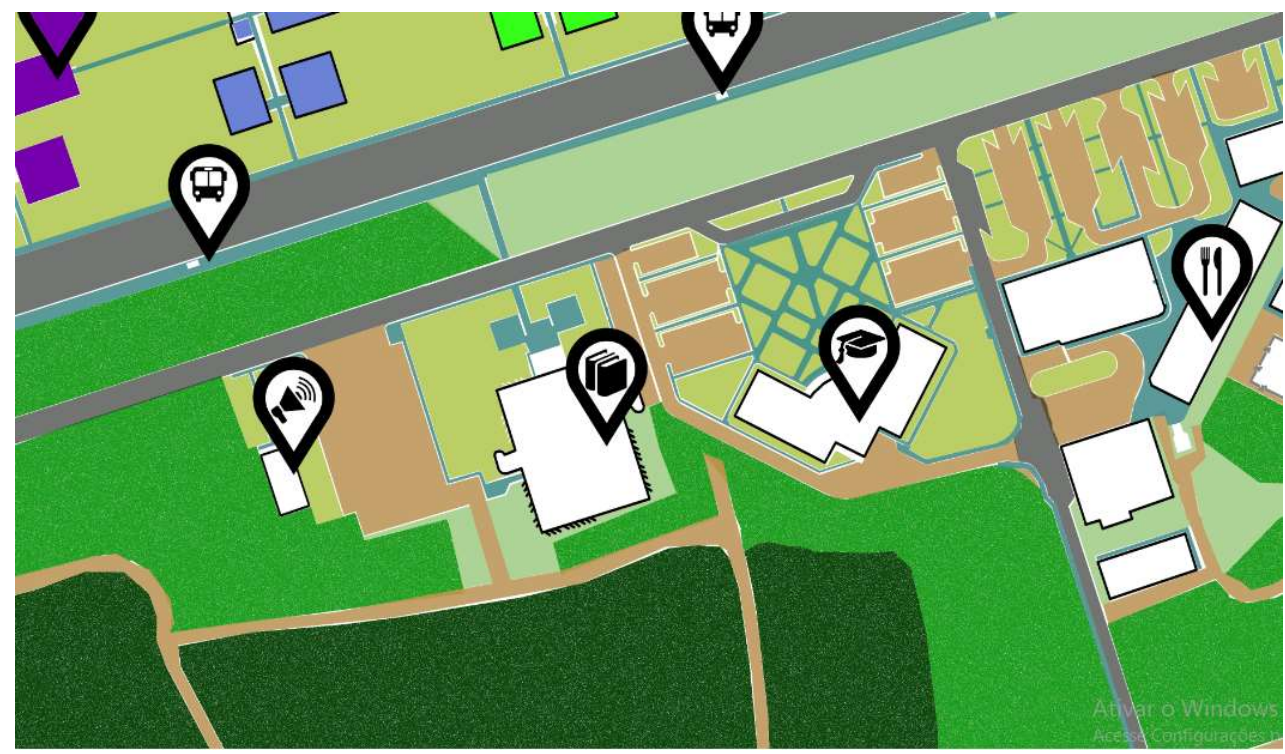

(Fonte: o próprio autor).

Como o ponto de referência dizia que a biblioteca estava à esquerda da Reitoria, o transeunte localiza seu objetivo no mapa e a partir disso ele poderá definir sua rota 


\section{CONCLUSÃO}

Conclui se que, o guia tem a intenção de facilitar o direcionamento de visitantes e transeuntes, desta reforça se a ideia da importância da fixação desse mapa em postos estratégicos como forma de orientação Como resultado final, foram confeccionados mapas de sinalização, identificando todos os prédios (Reitoria, Biblioteca, entre outros), módulos (1 ao 7), laboratórios, praças, restaurante universitário e residência universitária. A sugestão é que posteriormente esses mapas sejam aproveitados como sinalização, cofeccionados em placas e afixados em pontos estratégicos da universidade para que toda e qualquer pessoa possa transitar com orientação, já que, grande parte da população não tem formação, treinamento ou costume de se orientar calculando direções.

\section{REFERÊNCIAS}

ROMAgnoli, Roberta Carvalho. A CARTOGRAFIA E A RELAÇÃo PESQUISA E VIDA. 2009. 8 f. Tese (Doutorado) - Curso de Psicologia, Puc-Minas, Belo Horizonte, 2009. Disponível em: https:/www.scielo.br/pdf/psoc/v21n2/v21n2a03. Acesso em: 19 maio 2020..

RAMOS, Cristhiane da Silva. Visualização Cartográfica E Cartografia Multimídia. São Paulo: Unesp, 2005. 179 p.

NUNES, Mônica Balestrin. Cartografia e paisagem: o mapa como objeto de estudo. Revista do Instituto de Estudos Brasileiros, Brasil, n. 65, p. 96-119, dez. 2016.

International orienterring federation

Radiokuto 20 ,FI-00093 SLU Finland - http://www.orienteerung.org documento foi traduzido para o Português (Portugal) do original em Inglês "International Specification for Orienteering Maps" por António Aires, mediante autorização da Comissão de Mapas da Federação Internacional de Orientação e adaptado para o Português (Brasil) por Jocemar Riva, mediante autorização do Conselho de Mapeadores da CBO

SILVA, Renato. A arte de desenhar . Rio de Janeiro: Conquista, 1957.

SILVA, G. P. DA. Desenho de pesquisa . Fundação Escola Nacional de Administração

Pública- Enap. Brasília, 2018. 
Land Transport NZ and Transit NZ became the NZ Transport Agency.1 August 2008 